\title{
The pleasant fiction of Medicare solvency
}

\author{
Gilbert Berdine MD
}

\begin{abstract}
Medicare has always been insolvent. Claims of Medicare solvency have always been pleasant fictions based on accounting gimmicks. The imbalances between income and expenditures have become so large that the pleasant fiction can no longer be maintained by any serious person. The following discussion will explain the accounting gimmicks, place current imbalances in historic context, and conclude with possible changes in Medicare policy to limit future growth in expenditures.
\end{abstract}

Table II.B1 illustrates a snapshot of the current income and expenditures for Medicare and its components. Medicare Part A is the Hospital Insurance program. Total income for Part A was $\$ 341.7$ billion. Of this total, $\$ 303.3$ billion came from payroll taxes on employed workers. Another $\$ 26.9$ billion comes from taxation of benefits paid by beneficiaries. Part A is what people think of when Medicare is described as "health insurance." Workers pay in when they are young and collect benefits when they retire. However, expenditures exceeded income for Part A by $\$ 60.4$ billion. At the current rate, the so-called Part $A$ trust fund would be depleted in less than 4 years. The Trustees make an actuarial assessment for the so-called trust funds each year. The current assessment is for the so-called Part A trust fund to be depleted in 2026.

Part B is the outpatient Medicare program. Beneficiaries pay premiums each year to receive Part B benefits. Premiums covered only $\$ 111.2$ billion of the total expenditures of $\$ 418.6$ billion for Part B. A small amount of $\$ 1.8$ billion is an accounting gimmick of assessing "interest" on the so-called trust fund assets. The vast majority of the total remaining expenditures is covered by another accounting gimmick called transfer of General Revenue. General Revenue is that U.S.

Corresponding author: Gilbert Berdine Contact Information: Gilbert.Berdine@ttuhsc.edu DOI: 10.12746/swrccc.v10i42.995 budget item that is perpetually in deficit. The latest official budget deficit was $\$ 2.3$ trillion for fiscal year 2020 , but it is projected to be $\$ 3.4$ trillion for fiscal year 2021 . $^{2}$

Part $D$ is the drug benefit program. Total income for Part D was $\$ 105.8$ billion. Of that total, only $\$ 15.8$ billion comes from premiums, $\$ 11.6$ billion comes from revenue transfers from the States, and the majority of funds ( $\$ 77.7$ billion) is a transfer from General Revenue. Medicare has never been truly solvent. Part B has always been supported by General Revenue as has the newer Part $D$ program. Only Part A could ever claim to be solvent, but that is no longer true.

Figure II.D1 illustrates the growth in Medicare as a fraction of ability to pay. Parts $A, B$, and D are all increasing as a fraction of economic activity. The projected flattening of the trends are all recognitions that Medicare can never exceed total economic activity. One can see that Part $B$ is increasing faster than Part A and Part D. Growth in Part A has always been limited by a desire to preserve the pleasant fiction that Medicare was solvent. Part B need not have any such limitations as the U.S. government can borrow or the Federal Reserve can print the increased funds necessary for Part B.

Figure II.D2 illustrates the growth in Medicare income since the start of the program. Although payroll taxes contribute a large share of total income, growth in payroll taxes has been non-existent since about 1996. Transfers from General Revenue to the Part B and Part $D$ programs have been the main source of revenue growth for Medicare. Medicare consumes about $4 \%$ of GDP with transfers from General Revenue being about half of the total at the current time. The Trustees note that "Growth in general revenue financing as a share of GDP adds significantly to the Federal budget pressures."1 The Trustees further note that "The interrelationship between the Medicare program and the Federal budget is an important topic-one that will become increasingly critical over time as the general revenue requirements 
Table II.B1. Summary of Medicare data for calendar year 2020. Table II.B1 from the 2021 Medicare Trustees Report. ${ }^{1}$ Numbers are billions of dollars except for the average benefit numbers which are nominal dollars per year per beneficiary.

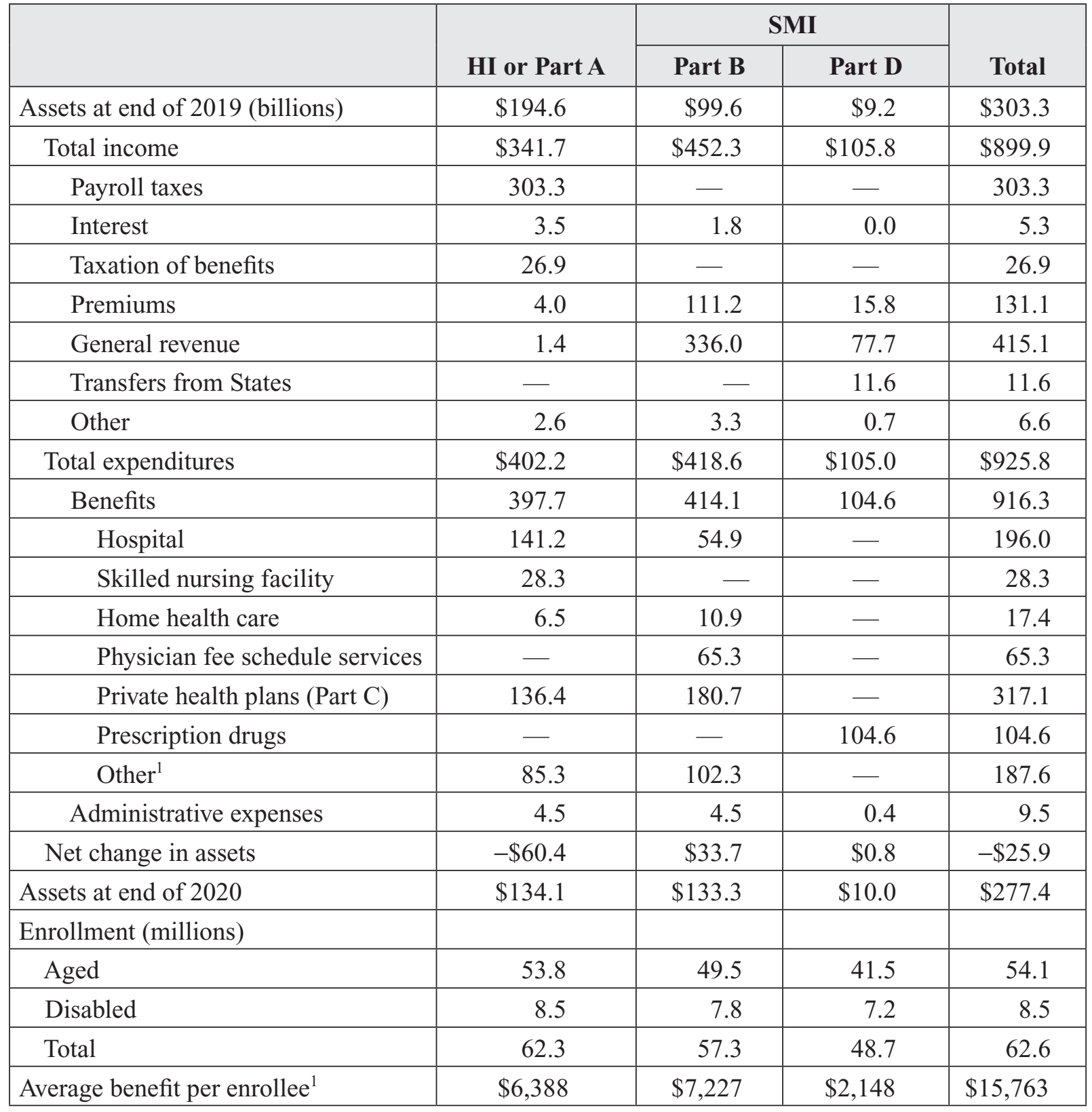

${ }^{1}$ Includes the impact of the Accelerated and Advance Payments Program, which was significantly expanded during 2020 due to the COVID-19 pandemic. Total payments of $\$ 107.1$ billion were made from the HI trust fund and the SMI Part B trust fund account.

Note: Totals do not necessarily equal the sums of rounded components. 
Figure II.D1. Medicare Expenditures as a percentage of gross domestic product (GDP). Figure II.D1 from the Trustees Report. ${ }^{1}$

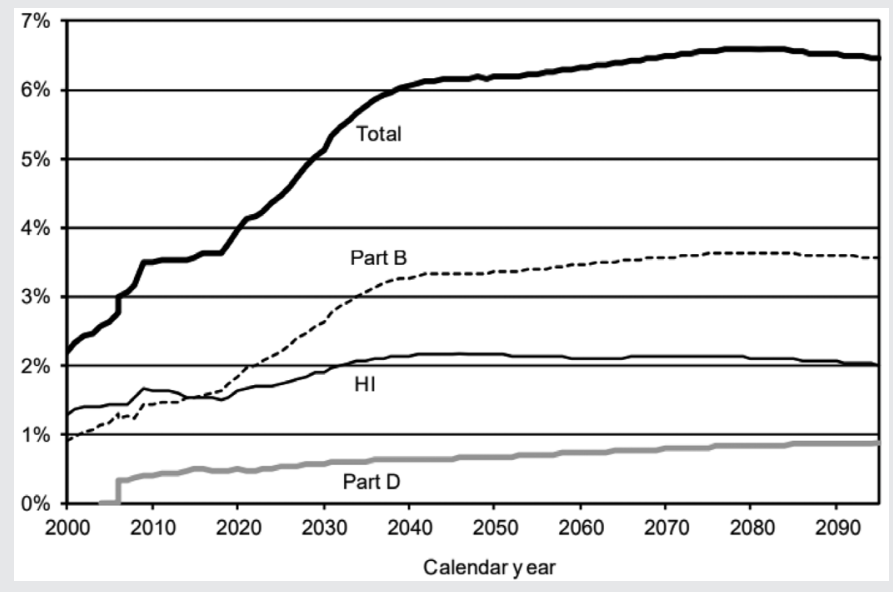

for SMI continue to grow."' SMI is the Supplementary Medical Insurance trust fund for Parts B and D.

Table II.F3 illustrates the growth of General Revenue transfers as a Medicare funding source as a percentage of total federal income tax revenues. The Trustees project that by 2095, Medicare will lay claim to almost $1 / 3$ of income tax revenue. Medicare will clearly be crowding out funding for other government spending.

COVID-19 was a shock to the Medicare system. Hospitalizations increased, which increased expenditures to Part A. A bonus payment was created for patients with a diagnosis of COVID-19, which created incentives to test every patient for COVID-19, label every patient with a positive test for COVID-19 as being a "case" of COVID-19, and admit every "case" of COVID-19 to the hospital. Outpatient services were shut down to protect health care workers from COVID-19. Outpatient surgeries were cancelled or deferred. Outpatient clinics were closed to anyone testing positive for COVID-19. These changes caused a decrease in expenditures to Part B. The changes also shifted urgent care from outpatient clinics to the emergency rooms, which are the gateways for hospital admission.

The Centers for Medicare and Medicaid Services bureaucracy will try to decrease future expenditures for
Figure II.D2. Medicare income by source as percentage of gross domestic product. Figure II.D2 in the Trustees Report. ${ }^{1}$

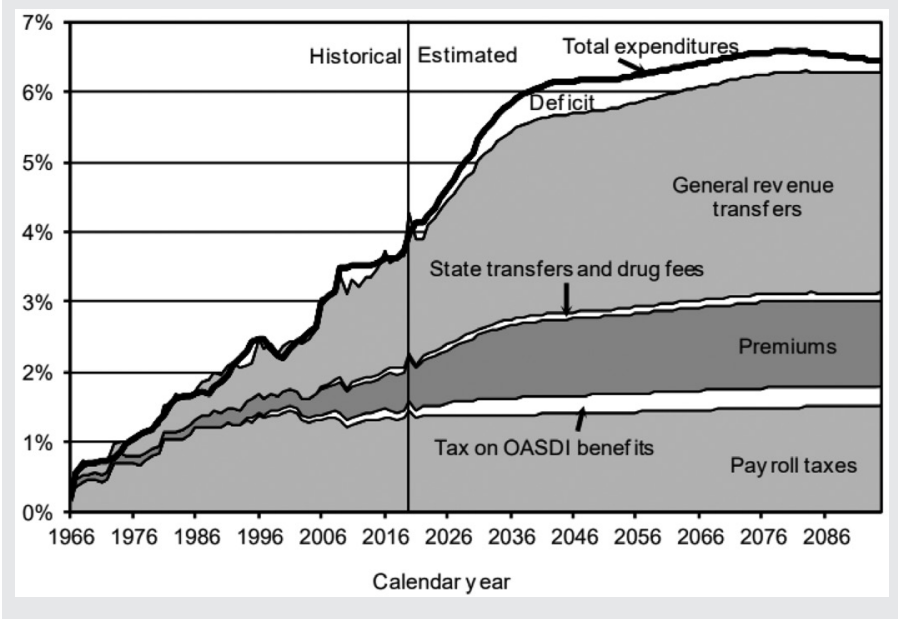

Part A. The most obvious change would be to reduce or eliminate the bonus payments for COVID-19 cases. Another obvious change would be a decrease in diagnosis related group (DRG) payments for hospital services. A variation on this change would be stricter rules for claiming a lucrative DRG payment. Possible examples include stricter criteria on what defines sepsis or acute respiratory failure.

The Centers for Medicare and Medicaid Services has created something called "observation" status. An "observation" patient is in the hospital like any other hospital admission, but the patient services are billed to Part B instead of Part A. The classic example of "observation" is a patient with chest pain and risk factors for coronary artery disease but who does not meet criteria for an acute myocardial infarction. The patient would be "observed" for 24-48 hours at which time the patient would either meet admission criteria and be converted to an inpatient billed under Part A or sent home. Historically, CMS preferred admission status since outpatient services are billed to Part $B$ on a fee for service basis while inpatients are billed to Part $A$ on a lump sum DRG basis. A two-midnight rule was included to prevent hospitals from abusing "observation" status by applying it to lengthy hospital stays. The current deficit in the Part A budget and surplus in the Part B budget now favors a shift of patients from 
Table II.F3. SMI transfers from General Revenue as a percentage of total personal and corporate federal income taxes. Table II.F3 from the Trustees report. ${ }^{1}$

\begin{tabular}{|c|c|}
\hline Fiscal Year & Percentage of Income Taxes 1 \\
\hline \multicolumn{2}{|c|}{ Historical data: } \\
\hline 1970 & $0.8 \%$ \\
\hline 1980 & 2.2 \\
\hline 1990 & 5.9 \\
\hline 2000 & 5.4 \\
\hline 2010 & 19.6 \\
\hline 2011 & 17.7 \\
\hline 2012 & 15.3 \\
\hline 2013 & 14.3 \\
\hline 2014 & 14.2 \\
\hline 2015 & 14.0 \\
\hline 2016 & 16.2 \\
\hline 2017 & 16.4 \\
\hline 2018 & 16.8 \\
\hline 2019 & 17.0 \\
\hline 2020 & 19.6 \\
\hline \multicolumn{2}{|c|}{ Intermediate estimate: } \\
\hline 2030 & 23.6 \\
\hline 2040 & 28.7 \\
\hline 2050 & 29.5 \\
\hline 2060 & 30.7 \\
\hline 2070 & 31.9 \\
\hline 2080 & 32.7 \\
\hline 2090 & 32.6 \\
\hline 2095 & 32.5 \\
\hline
\end{tabular}

${ }^{1}$ Includes the Part D prescription drug benefit beginning in 2006. inpatient status to "observation" status even though the shift would be more expensive. A creative change to the "observation" status could either come from CMS or hospitals.

Keywords: Medicare, Medicaid, budget, government funding

Article citation: Berdine G. The pleasant fiction of Medicare solvency. The Southwest Respiratory and Critical Care Chronicles 2022;10(42):54-57

From: Department of Internal Medicine, Texas Tech University Health Sciences Center, Lubbock, Texas

Submitted: $1 / 1 / 2022$

Accepted: $1 / 9 / 2022$

Conflicts of interest: none

This work is licensed under a Creative Commons Attribution-ShareAlike 4.0 International License.

\section{REFERENCES}

1. 2021 Annual report of the boards of trustees of the federal hospital insurance and federal supplementary medical insurance trust funds. https://www.cms.gov/files/document/2021medicare-trustees-report.pdf

2. What Is the Current U.S. Federal Budget Deficit? https://www. thebalance.com/current-u-s-federal-budget-deficit-3305783 